\title{
A transient increase in MHC-II low monocytes after experimental infection with Avibacterium paragallinarum (serovar B-1) in SPF chickens
}

\author{
Karla Lucía F. Alvarez ${ }^{*}$, Astrid Poma-Acevedo and Manolo Fernández-Díaz
}

\begin{abstract}
Infectious coryza (IC), an upper respiratory tract disease affecting chickens, is caused by Avibacterium paragallinarum. The clinical manifestations of IC include nasal discharge, facial swelling, and lacrimation. This acute disease results in high morbidity and low mortality, while the course of the disease is prolonged and mortality rates are increased in cases with secondary infections. Studies regarding the immune response in infected chickens are scarce, and the local immune response is the focal point of investigation. However, a large body of work has demonstrated that severe infections can impact the systemic immune response. The objective of this study was to evaluate the systemic effects of Avibacterium paragallinarum (serovar B-1) infection on immune cells in specific pathogen-free (SPF) chickens. The current study revealed the presence of a transient circulating monocyte population endowed with high phagocytic ability and clear downregulation of major histocompatibility complex class II (MHC-II) surface expression. In human and mouse studies, this monocyte population (identified as tolerant monocytes) has been correlated with a dysfunctional immune response, increasing the risk of secondary infections and mortality. Consistent with this dysfunctional immune response, we demonstrate that B cells from infected chickens produced fewer antibodies than those from control chickens. Moreover, T cells isolated from the peripheral blood of infected chickens had a lower ability to proliferate in response to concanavalin A than those isolated from control chickens. These findings could be related to the severe clinical signs observed in complicated IC caused by the presence of secondary infections.
\end{abstract}

Keywords: Avibacterium paragallinarum, infectious coryza, systemic immune response, monocytes, MHC-II

\section{Introduction}

Avibacterium paragallinarum (Av. paragallinarum) is a gram-negative bacterium that has been isolated worldwide and is the aetiological agent of infectious coryza (IC), a disease that contributes to significant economic losses in the poultry industry. Clinical signs of IC include nasal discharge, facial swelling, and lacrimation. This disease is associated with reduced egg production, poor growth, and high morbidity $[1,2]$. However, in cases with secondary infections, exacerbation of the clinical signs of the disease and increased mortality are observed [3-6].

*Correspondence: karla.alvarez@farvet.com; karlalucia220@gmail.com Research and Development Laboratories, FARVET, Carretera

Panamericana Sur No 766 Km 198.5, Ica, Peru
The causal agent of the disease is classified by the Kume haemagglutinin serotyping scheme into nine serovars (A-1, A-2, A-3, A-4, B-1, C-1, C-2, C-3, and C-4) [7]. All serovars exhibit tropism related to the upper respiratory tract, including the involvement of nasal passages, infraorbital sinuses, and paranasal sinuses.

The efficiency of the local immune system during infection has been evidenced, as different studies have reported a gradual decrease in the Av. paragallinarum abundance in infected tissue $[6,8]$. Despite the importance of the immune system in the progression of the disease, few studies have evaluated the role of cells or molecules associated with the immune response. Furthermore, although relevant information was obtained, the studies focused on the local immune response by 
analysis of nasal tissue samples $[9,10]$. However, the prognosis of a disease is a result of a more complicated interaction between the local and systemic immune responses. Studies in mice and humans have demonstrated that local infections or trauma also induce a systemic immune response through the release of damage-associated molecular patterns (DAMP) from damaged or necrotic cells [11, 12]. Moreover, studies in chickens (also demonstrated in humans and mice) have shown that in response to a biological stimulus, macrophages and other cells of the immune system secrete pro- and anti-inflammatory cytokines that are released into the circulatory system to elicit a systemic immune response [13-16]. One of the target populations of these cytokines is monocytes, described as a heterogeneous population in the avian system, which have chemotactic and phagocytic activities and are capable of generating a respiratory burst [17-19]. During infectious or severe inflammatory insult in humans and mice, this population has an important role in compensatory anti-inflammatory response syndrome (CARS), a biological process that is necessary to prevent overwhelming inflammation and avoid organ failure [20,21]. In addition to the benefits of this orchestrated immune response, a prolonged anti-inflammatory response results in immunoparalysis that is characterized by impaired immunity, which is responsible for a patient's vulnerability to secondary infections and is a common cause of death [22].

As mentioned above, localized infections can modulate the systemic immune response via diverse mechanisms. Thus, the objective of this study was to evaluate the systemic effects of $A v$. paragallinarum infection on immune cells in specific pathogen-free (SPF) chickens, focusing on the role that mononuclear cells, including monocytes as well as $\mathrm{T}$ and $\mathrm{B}$ lymphocytes, could play in this important poultry disease.

\section{Materials and methods \\ Birds}

Forty-eight SPF 16- or 37-week-old white leghorn chickens were maintained and fed ad libitum. SPF chickens were obtained from Charles River Laboratories (Wilmington, MA, USA), and all chickens were housed in the SPF area of FARVET. The animals were euthanized by a qualified veterinarian using cervical dislocation without anaesthesia, following the American Veterinary Medical Association (AVMA) guidelines.

\section{Bacterial strain}

The well-characterized $A v$. paragallinarum isolate FARPER-107 (serovar B-1) was used in this study [23]. This bacterium was isolated in 2013 from an infectious coryza outbreak on a broiler farm in Arequipa, Peru, as described by Morales and collaborators [23].

Experimental infection of chickens with Av. paragallinarum As a model for infectious coryza, SPF chickens (16- or 37-week-old) were experimentally infected with $A v$. paragallinarum (serovar B-1) via intrasinus instillation, following the same methodology previously reported [23]. Chickens in the control group were paired according to sex and age. Briefly, Av. paragallinarum was inoculated into 7-day-old SPF embryonic eggs. After $24 \mathrm{~h}$, the yolks were collected, and $200 \mu \mathrm{L}$ of yolk containing $10^{6}-10^{7}$ $\mathrm{PFU} / \mathrm{mL}$ bacteria were inoculated into each chicken via intrasinus instillation. The clinical signs observed in each chicken were recorded after inoculation and scored according to a previously reported scale as follows: 0 , no signs; 1 , nasal discharge or slight facial swelling; 2, nasal discharge and moderate facial swelling; 3 , abundant nasal discharge and severe facial swelling; and 4, the same signs observed in 3 with the addition of swollen wattles and/or conjunctivitis [24].

\section{Bacterial detection by PCR}

Av. paragallinarum was isolated from the nasal cavity on day 4 or 6 post infection using a wet swab and was subsequently transported to the laboratory in ice-cold D-PBS (Sigma-Aldrich, St. Louis, MO, USA, Cat. no. D5773-50L).

Genomic DNA was extracted using a commercial QIAamp MinElute Virus Spin Kit (Qiagen, Hilden, Germany, Cat. no. 57704) according to the manufacturer's instructions. The target region for PCR included the hypervariable region of the hmtp210 gene [25], which was amplified with the following primers: forward primer, GGC GAT TTA ACA CGG GAG TC, and reverse primer, TCAT ACC AGA TAA ACG GAT ACCT. A Q5 High-Fidelity PCR Kit (New England Bio Labs, Cat. no. E0555) containing pre-mixed dNTP, Taq polymerase, $\mathrm{MgCl}_{2}$ and buffer at optimum concentrations was used for PCR. The thermal cycling steps used for amplification were as follows: $98^{\circ} \mathrm{C}$ for $30 \mathrm{~s} ; 35$ cycles at $98^{\circ} \mathrm{C}$ for $10 \mathrm{~s}, 58.6{ }^{\circ} \mathrm{C}$ for $15 \mathrm{~s}$, and $72{ }^{\circ} \mathrm{C}$ for $20 \mathrm{~s}$; and a final step at $72{ }^{\circ} \mathrm{C}$ for $2 \mathrm{~min}$. The PCR products, $194 \mathrm{bp}$ in length, were subjected to agarose gel electrophoresis on $2 \%$ agarose gels, after which they were visualized and imaged under ultraviolet light (Azure Biosystems, Dublin, CA, USA).

\section{Isolation and culture of peripheral blood mononuclear cells (PBMC)}

Blood was collected from the brachial wing vein into vacutainers (Vacutest Kima, PD, Italy, Cat. no. 12010) containing heparin lithium as an anticoagulant. 
Mononuclear cells were isolated from blood by density gradient centrifugation $(400 \times g$ for $30 \mathrm{~min}$ at room temperature, without braking) using Histopaque-1077 (Sigma-Aldrich, Cat. no. 10771). Thereafter, the cells were washed twice with D-PBS at $300 \times g$ for $10 \mathrm{~min}$ at room temperature. The cells were resuspended in D-PBS containing 5\% foetal bovine serum (FBS; HyClone, GE Healthcare, Logan, UT, USA, Cat. no. SV30180.03) or in cell culture medium and were counted after staining with $0.4 \%$ trypan blue solution (Sigma-Aldrich, Cat. no. 93595-50ML).

\section{Phagocytosis assays}

PBMC were seeded in 24-well plates and cultured in serum-free medium (FARMEM, a medium developed inhouse at FARVET, proprietary) in the presence of fluorescent beads (Polyscience, Warrington, PA, USA, Cat. no. 17844) pre-diluted in culture medium. Phagocytosis was allowed to proceed for $24 \mathrm{~h}$ in a humidified $5 \% \mathrm{CO}_{2}$ incubator at $41{ }^{\circ} \mathrm{C}$. A control plate was stored at $4{ }^{\circ} \mathrm{C}$. Subsequently, cells were detached with $20 \mathrm{mM}$ EDTA (Calbiochem, San Diego, CA, USA, Cat. no. 324503) at room temperature. Immunostaining was performed at $4{ }^{\circ} \mathrm{C}$ using a mouse anti-chicken monocyte/macrophage$\mathrm{PE}$ antibody (detailed in the following paragraph). Finally, cells were incubated at $4{ }^{\circ} \mathrm{C}$ with 7 -aminoactinomycin D (7-AAD, BD Biosciences, San Jose, CA, USA, Cat. no. 8200-02) and were then analysed by flow cytometry.

\section{Mononuclear cell proliferation assay}

Mononuclear cells isolated as described above were seeded in 96-well, round-bottom plates in the presence or absence of $1 \mu \mathrm{g} / \mathrm{mL}$ concanavalin A (Sigma, Cat. no. C5275-5MG) for $72 \mathrm{~h}$. Next, $25 \mu \mathrm{M}$ EdU (Thermo Fisher Scientific, Waltham, MA, USA, Cat. no. A10044) reagent was added $16 \mathrm{~h}$ before termination of culture. The click reaction and staining were performed according to a previously published protocol [26]. Briefly, cells were labelled with mouse anti-chicken CD4-Alexa Fluor ${ }^{\circledR}$ 647 (detailed in the following paragraph) and fixed with $2 \%$ formaldehyde. Subsequently, cells were incubated with the click reaction reagents $(6 \mu \mathrm{M}$ fluorescent azide, $0.3 \mathrm{mM} \mathrm{CuSO}_{4}$, and $100 \mathrm{mM}$ ascorbic acid).

\section{Fluorescent cell staining}

To prevent non-specific binding, mononuclear cells were incubated for $10 \mathrm{~min}$ at $4{ }^{\circ} \mathrm{C}$ with a $1: 100$ dilution of normal mouse serum (Abcam, Cambridge, MA, USA, Cat. no. ab7486) prior to antibody addition. Thereafter, cells were labelled with directly conjugated monoclonal antibodies (detailed in the following paragraph). All antibodies were diluted to the optimal concentration before use. Cell staining was performed at $4{ }^{\circ} \mathrm{C}$ for $20 \mathrm{~min}$. Finally, cells were filtered through a $44 \mu \mathrm{M}$-pore size nylon mesh (Merck, Darmstadt, Germany, Cat. no. NY4100010) and analysed by flow cytometry.

\section{Antibodies and flow cytometry reagents}

Mouse anti-chicken CD4-Alexa Fluor ${ }^{\circledR} 647$ (clone CT-4, Cat. no. 821031), mouse anti-chicken CD8 $\alpha-\mathrm{PE}$ (clone 3-298, Cat. no. 8405-09), mouse anti-chicken CD3-SPRD (clone CT-3, Cat. no. 8200-13), and mouse anti-chicken Bu-1-FITC (clone AV20, Cat. no. 8395-02) antibodies were purchased from SouthernBiotech (Birmingham, AL, USA). The mouse anti-chicken monocyte/macrophagePE antibody (clone 5K102, also called clone KUL01, Cat. no. M4520-17) was purchased from USBiological (Salem, MA, USA). Mouse anti-chicken MHC class IIFITC (clone 2G11, Cat. no. ab24882), mouse anti-chicken MHC class I-FITC (clone F21-2, Cat. no. ab24881), and biotin mouse anti-chicken TCR gamma delta (clone TCR1, Cat. no. ab25151) antibodies were purchased from Abcam. Streptavidin Alexa Fluor 750 conjugate (Cat. no. S21384) and Sytox blue dead cell stain (Cat. no. S34857) were purchased from Thermo Fisher Scientific (Waltham, MA, USA). The viability determination reagent 7-AAD (Cat. no. 8200-02), was purchased from BD Biosciences (San Jose, CA, USA).

\section{Whole blood cell staining}

Using a reverse pipetting technique, $100 \mu \mathrm{L}$ of heparinized blood was transferred into each tube and incubated with the mouse anti-chicken MHC class II-FITC (detailed above) and mouse anti-chicken monocyte/macrophagePE (detailed above) antibodies for $20 \mathrm{~min}$ in the dark at room temperature. After 5 min of incubation with $400 \mu \mathrm{L}$ of 1X BD FACS lysis solution (BD, Cat. no. 349202), cells were washed twice with $5 \mathrm{~mL}$ of PBS containing 5\% FBS at $300 \times g$ for $5 \mathrm{~min}$ at room temperature. Finally, cells were resuspended in $1 \mathrm{~mL}$ of D-PBS, and $100 \mu \mathrm{L}$ of AccuCheck Counting Beads (Thermo Fisher Scientific, Cat. no. PCB100) was added using the reverse pipetting technique. The absolute count was obtained according to the manufacturer's instructions.

\section{Flow cytometry}

Flow cytometry was performed using a BD FACSMelody flow cytometer (BD Biosciences, USA) equipped with two lasers (488 nm and $635 \mathrm{~nm}$ ) and a Gallios flow cytometer (Beckman Coulter, USA) equipped with three lasers $(488 \mathrm{~nm}, 635 \mathrm{~nm}$, and $405 \mathrm{~nm})$. The data were analysed using FlowJo software v10.6.1 (BD Biosciences, USA). 


\section{Vaccination against Newcastle disease virus (NDV)}

Fourteen 16-week-old SPF chickens were divided equally into 2 groups. One group was infected as described above. Five days post infection, each chicken in each group was vaccinated via the eye-drop route with a $30 \mu \mathrm{L}$ volume containing $10^{7} 50 \%$ egg infective dose $\left(\mathrm{EID}_{50} / \mathrm{mL}\right)$ of a non-pathogenic NDV strain (LaSota). On days 0 and 14 post vaccination, serum samples were collected for quantification of anti-NDV antibodies by ELISA.

\section{ELISA}

Antibody titres were determined by indirect ELISA (IDEXX, Westbrook, Maine, USA, Cat. no. 99-09263) following the manufacturer's instructions. Briefly, $100 \mu \mathrm{L}$ of each serum sample and $100 \mu \mathrm{L}$ of the negative and positive control samples were dispensed into wells and incubated for $30 \mathrm{~min}$. The plates were then washed and incubated with $100 \mu \mathrm{L}$ of conjugate per well for $30 \mathrm{~min}$. Subsequently, the plates were washed, and $100 \mu \mathrm{L}$ of substrate solution was added per well. The reaction was terminated after the addition of $100 \mu \mathrm{L}$ stop solution. The plates were read using an Epoch 2 microplate reader (BioTek, USA) at $450 \mathrm{~nm}$. The data were analysed, and the sample-to-positive $(\mathrm{S} / \mathrm{P})$ ratio was calculated.

\section{Statistical analysis}

All quantitative data were analysed using GraphPad Prism version 6.1 (GraphPad Software, San Diego, CA, USA). The Mann-Whitney test was utilized to evaluate differences between groups. $\mathrm{p} \leq 0.05$ was considered to indicate a statistically significant difference.

\section{Results}

The monocyte population increased in infectious coryza expresses low levels of MHC-II molecules

In this study, we experimentally infected SPF chickens with Av. paragallinarum (serovar B-1) via intrasinus instillation to establish a model of infectious coryza. PCR was used either 4 or 6 days post infection to confirm the presence of $A v$. paragallinarum in nasal mucus samples from infected birds, and a scoring system [24] was used to assess the clinical signs observed (Additional file 1). Representative agarose gel electrophoresis results of PCR products amplified with primers corresponding to the sequences of the hypervariable region in the hmtp 210 gene are shown in Additional file 2.

To determine the role of immune cells in chickens with infectious coryza, we first measured the percentages of $\mathrm{T}$ cells $\left(\mathrm{CD}^{+}{ }^{+} \mathrm{TCR} \alpha \beta^{+}, \mathrm{CD}^{+} \mathrm{CD} 4^{+} \mathrm{TCR} \alpha \beta^{+}\right.$, $\mathrm{CD}^{+} \mathrm{CD}^{+}{ }^{+} \mathrm{TCR} \alpha \beta^{+}, \mathrm{CD} 3^{+} \mathrm{TCR} \gamma \delta^{+}$, and $\mathrm{CD}^{+} \mathrm{CD}^{+}$ TCR $\left.\gamma \delta^{+}\right)$, B cells $\left(\mathrm{Bu}-1^{+}\right)$, monocytes $\left(\mathrm{MRCL} 1-\mathrm{B}^{+}\right)$, and other antigen-presenting cells $\left(\mathrm{MRC} 1 \mathrm{~L}-\mathrm{B}^{-} \mathrm{MHCII}^{+}\right)$in peripheral blood samples from experimentally infected chickens ( $\mathrm{n}=5,37$ week-old) and uninfected chickens $(\mathrm{n}=5,37$ week-old) using flow cytometry. As shown in Figure $1 \mathrm{~B}$, on day 4 post infection, the percentage of monocytes was higher in infected animals than in control animals $(4.028 \pm 2.8 \%$ vs $1.19 \pm 0.32 \%, \mathrm{p}=0.032)$. No significant differences were observed in other cell populations that were evaluated. To quantitatively determine the number of monocytes, we infected 16-week-old SPF chickens (infected animals: $n=6$; control animals: $n=7$ ), and on day 4 post infection, we estimated the absolute number of monocytes based on the acquired bead count using whole blood. As depicted in Figure $1 \mathrm{C}$, the absolute number and percentage of circulating monocytes was higher in infected animals than in control animals $(4996.2 \pm 2536$ cells $/ \mu \mathrm{l}$ vs $1412.1 \pm 734.8 \mathrm{cells} / \mu \mathrm{l}$, $\mathrm{p}=0.0082$ and $0.5 \pm 0.01 \%$ vs $0.09 \pm 0.001 \%, \mathrm{p}=0.0058$, respectively).

It has been reported that chicken monocytes express MHC-II molecules [27, 28]. The importance of this molecule is evidenced by its phylogenetic conservation between species, as well as its crucial role in the

\footnotetext{
(See figure on next page.)

Figure 1 An increased number of monocytes characterized by low expression levels of MHC-II molecules is observed in chickens infected with Av. paragallinarum. Mononuclear cells isolated from blood samples were incubated with different antibody cocktails. A Gating strategy used to analyse mononuclear cells. We gated out debris, doublets, and dead cells (Sytox blue positive cells), and evaluated the percentages of $\mathrm{CD}^{+} \mathrm{TCR} \gamma \delta^{+}$cells, $\mathrm{CD} 3^{+} \mathrm{TCR} \gamma \delta^{-}$cells, and Bu- $1^{+}$cells (B cells). The percentages of $\mathrm{CD}^{+}$and $\mathrm{CD} 8 \mathrm{a}^{+}$cells were evaluated inside the $\mathrm{CD} 3^{+} \mathrm{TCR} \gamma \delta^{-}$ gate. The percentage of $\mathrm{CD} 8 \mathrm{a}^{+}$cells was also evaluated inside the $\mathrm{CD} 3^{+} \mathrm{TCR} \gamma \delta^{+}$gate. The dashed arrow indicates the strategy used to evaluate the populations of monocytes (MRC1L-B $)$ and other APC $\left(\mathrm{MHC}-I^{+} \mathrm{MRC} 1 \mathrm{~L}-\mathrm{B}^{-}\right)$using another antibody cocktail. B Quantitative data regarding the percentages of $\mathrm{CD}^{+}{ }^{+} \mathrm{TCR} \gamma \delta^{-}$cells, $\mathrm{CD} 3^{+} \mathrm{CD} 4^{+} \mathrm{TCR} \gamma \delta^{-}$cells, $\mathrm{CD} 3^{+} \mathrm{CD} 8 \mathrm{a}^{+} \mathrm{TCR} \gamma \delta^{-}$cells, $\mathrm{Bu}-1^{+}$cells, $\mathrm{CD} 3^{+} \mathrm{TCR} \gamma \delta^{+}$cells, $\mathrm{CD} 3^{+} \mathrm{TCR} \gamma \delta^{+} \mathrm{CD} 8 \mathrm{a}^{+}$ cells, monocytes and other APC in infected and uninfected animals. The data are presented as percentages of Sytox blue negative cells. Each dot represents an animal. Significant differences are indicated by ${ }^{*} p=0.0317$. The results are expressed as the mean \pm standard deviation values. A total of 30,000 events per sample were acquired using a Gallios flow cytometer. C The figure on the left shows the percentage of monocytes in whole blood. The figure on the right shows the absolute monocyte counts. D PBMC or whole blood were used to evaluate MHC-II expression in the monocyte population and $\mathrm{MHC}-\mathrm{II}^{+} \mathrm{MRC} 1 \mathrm{~L}-\mathrm{B}^{-}$population. The gate used to identify this population is shown in $\mathbf{A}$. Each dot represents an animal, and the mean values \pm standard deviations are indicated by the bars. Significant differences are indicated by ${ }^{*} p=0.0286$ and ${ }^{* *} p=0.0023$. A total of 30,000 events were acquired for analysis of PBMC, and 300,000 events per sample were acquired for analysis of whole blood samples using a FACSMelody flow cytometer.
} 


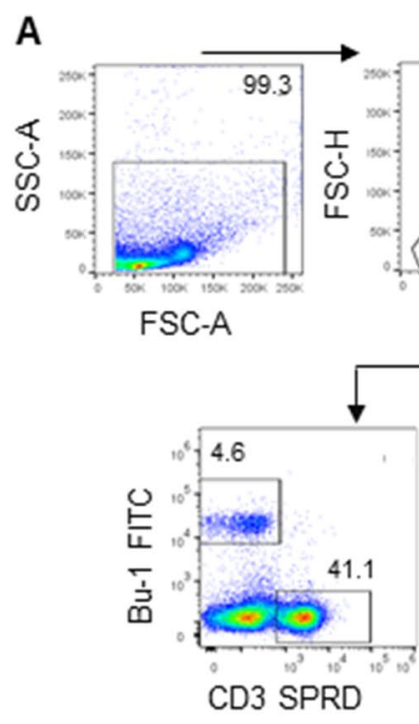

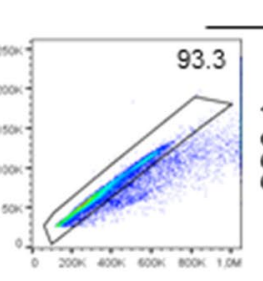

FSC-A

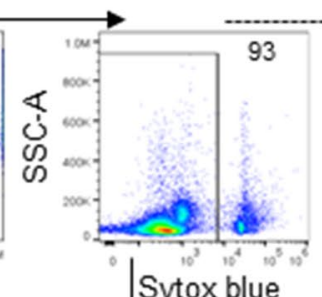

Sytox blue

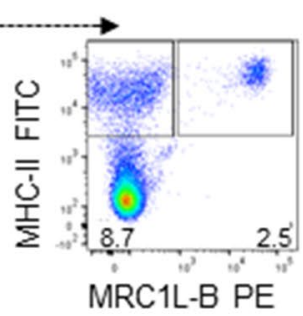

MRC1L-B PE

B
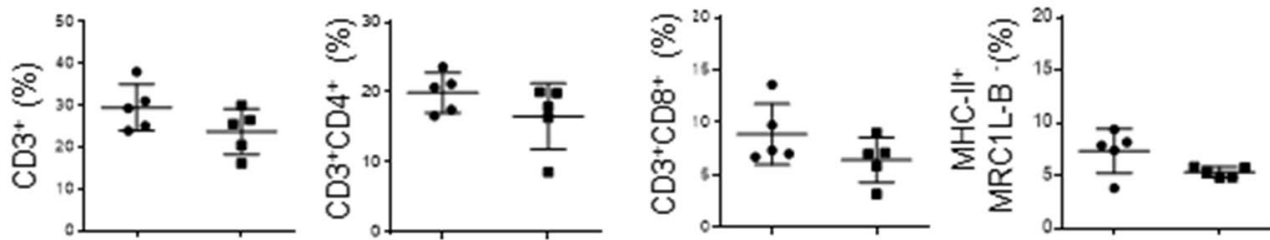

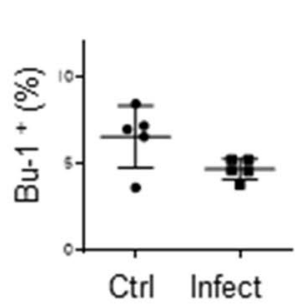
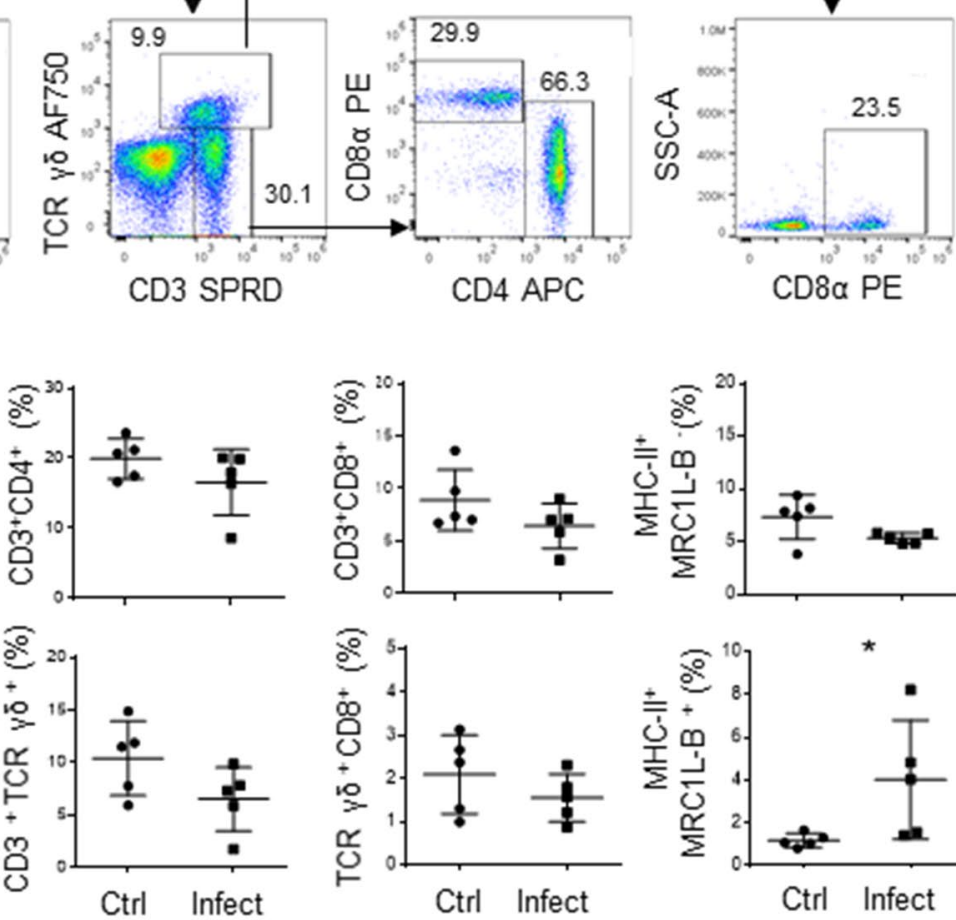

C

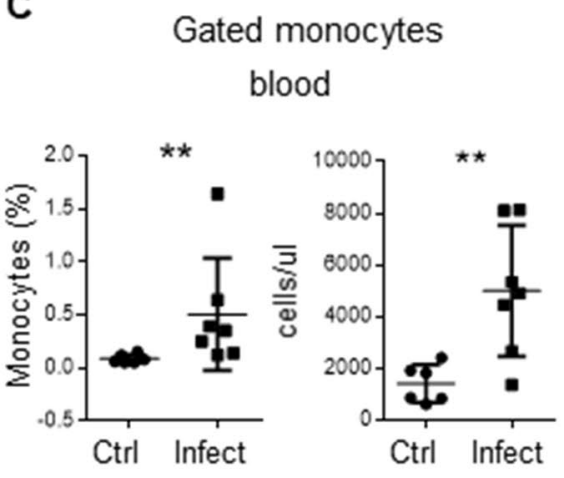

D

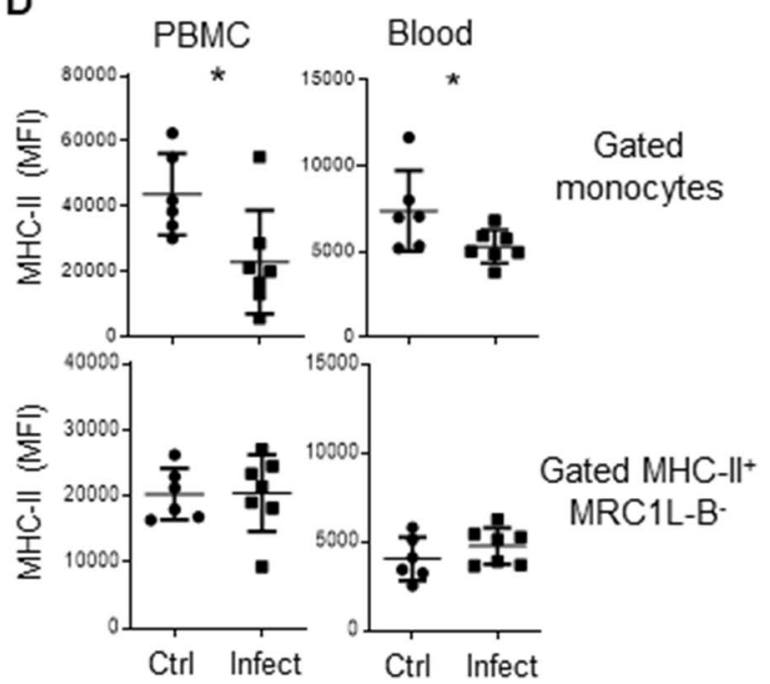


functioning of the immune system, including in antigen presentation, rejection of tissue grafts in response to histocompatibility antigens, and resistance to viral diseases [29]. Therefore, using the same experimental group, we evaluated whether MHC-II expression was altered in monocytes from infected animals. As shown in Figure 1D, the mean fluorescence intensity (MFI) of MHC-II was lower in monocytes isolated through density gradient centrifugation from infected animals than in those isolated from control animals $(22,890.4 \pm 15,891.3$ MFI vs $43,655 \pm 12,515$ MFI, $p=0.021)$. The same pattern was observed in directly stained samples of whole blood from infected and control animals (5293 \pm 967 MFI vs $7781.6 \pm 2392.7$ MFI, $\mathrm{p}=0.035)$. In this experimental group, similar levels of $\mathrm{MHC}-\mathrm{II}^{+}$expression were observed on $\mathrm{MRC} 1 \mathrm{~L}-\mathrm{B}^{-} \mathrm{MHCII}^{+}$cells isolated from infected and control animals. The flow cytometry protocol used to analyse the samples of whole blood is shown in Additional file 3.

\section{MHC-II low monocytes endowed with high phagocytic activity are present during a short period post infection}

To further define the period during which MHC-II ${ }^{\text {low }}$ monocytes circulate, we evaluated this peripheral blood mononuclear cell (PBMC) population 4, 9, 12, and 25 days post infection in 37-week-old chickens (infected animals: $n=5$, control animals: $n=5$ ). As shown in Figure $2 \mathrm{~A}, \mathrm{~B}$, on day 4 post infection, we observed that MHC-II expression was lower in infected animals than in control animals $(21,796.8 \pm 6210.2$ MFI vs $46,646.8 \pm 13,243$ MFI, $p=0.016)$ and that the percentage of monocytes was higher in infected animals $(4.6 \pm 0.05 \%$ vs $1.73 \pm 0.01 \%, p=0.032$ ). Nine days post infection, MHC-II expression remained lower in infected animals than in control animals $(21,459.3 \pm 3473.4$ MFI vs $12,660.6 \pm 2605.3 \mathrm{MFI}, \mathrm{p}=0.016$ ); however, the percentage of monocytes was similar in both groups $(1.67 \pm 0.9 \%$ vs $1.12 \pm 0.32 \%, \mathrm{p}=0.4)$. No significant differences were observed between the experimental and control groups regarding the percentage of circulating monocytes and MHC-II expression 12 and 25 days post infection. In contrast to the low expression of MHC-II in monocytes from infected animals observed 4 days post infection, the MFI of MHC-I expression on monocytes was slightly higher in infected samples than in control samples $(4841 \pm 1609$ MFI vs $2534 \pm 699$ MFI, $\mathrm{p}=0.05$ ) (Figure $2 \mathrm{C}, \mathrm{D}$ ), while the MHC-I expression values were similar between the groups 12 days post infection $(1252 \pm 372$ MFI vs $1396 \pm 539$ MFI, $\mathrm{p}=0.9)$. On the other hand, on day 4 post infection, MHC-II expression was lower in MRC1L$\mathrm{B}^{-} \mathrm{MHCII}^{+}$cells that were isolated from infected animals compared to those isolated from control animals $(16,824.2 \pm 3248.1$ MFI vs $22,375.4 \pm 3195.5$ MFI, $\mathrm{p}=0,0317$ ) (Figure 2A).

There are reports that some bacteria or viruses can reduce the surface expression of MHC-II molecules as an immune evasion mechanism [30, 31]. Considering that Av. paragallinarum has been recovered from naturally sterile sites such as the liver, spleen, and hocks [4], we evaluated the presence of bacterial DNA in lysed PBMC or sorted monocytes via conventional PCR. Although we detected the housekeeping gene GAPDH, we did not detect the presence of bacterial DNA in the PBMC.

It has been reported that chicken monocytes are capable of phagocytosis [32]; therefore, we examined whether the phagocytic ability of these monocytes is decreased, increased, or unchanged during infection. To address this question, we cultured PBMC from these chickens for $24 \mathrm{~h}$ in the presence of yellow-green (YG) fluorescent beads. To determine that the fluorescence signal originated from internalized beads and not from attached surface beads, a control plate was stored at $4{ }^{\circ} \mathrm{C}$. The flow cytometry protocol used to analyse the phagocytic activity of the monocytes is shown in Figure 3A. Four days post infection, we observed that the percentage of phagocytizing monocytes was higher in samples from infected animals than in samples from control animals $(29.84 \pm 0.14 \%$ vs $4.38 \pm 0.01 \%, \mathrm{p}=0.0079)$, as shown in Figure $3 \mathrm{~B}$. Nine days post infection, the phagocytic activity in both infected and uninfected samples started to return to baseline values $(4.96 \pm 0.05 \%$ vs $1.98 \pm 0.002 \%$, $\mathrm{p}=0.0952$ ), and phagocytic activity was similar in both groups $(0.47 \pm 0.002 \%$ vs $0.29 \pm 0.0012 \%, \quad \mathrm{p}=0.53)$ 12 days post infection.

\footnotetext{
(See figure on next page.)

Figure 2 Evaluation of monocytes and surface expression levels of MHC-II and MHC-I molecules on different days post infection.

Mononuclear cells were isolated from the blood of infected and uninfected animals at 4, 9, 12, and 25 days post infection via density gradient centrifugation using Histopaque-1077. A MHC-II surface expression on monocytes and MHC-II+ MRC1L-B- cells was evaluated using the analysis protocol shown in Figure 1A. Each dot represents an animal. Significant differences are indicated $b y{ }^{*} p=0.0159$. B Each dot represents an experimental group $(n=5)$ evaluated on different days post infection. Significant differences are indicated by ${ }^{*} p=00,317$. C Histogram showing the different levels of MHC-I expression on monocytes from infected and uninfected animals. D MHC-I surface expression in the monocyte population was evaluated on different days post infection. The results are expressed as the mean \pm standard deviation values. A total of 30,000 events per sample were acquired using a Gallios flow cytometer.
} 
A Gated monocytes

Day 4 p.i.

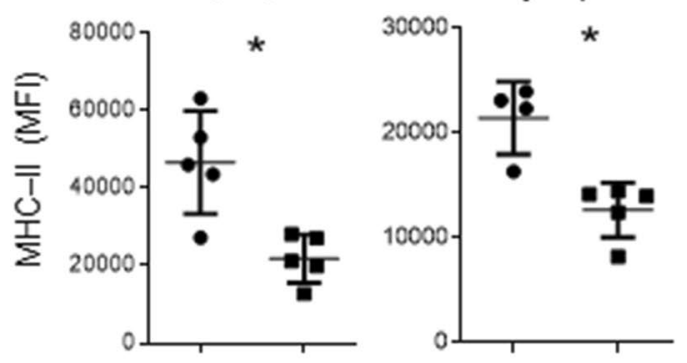

Day 12 p.i.
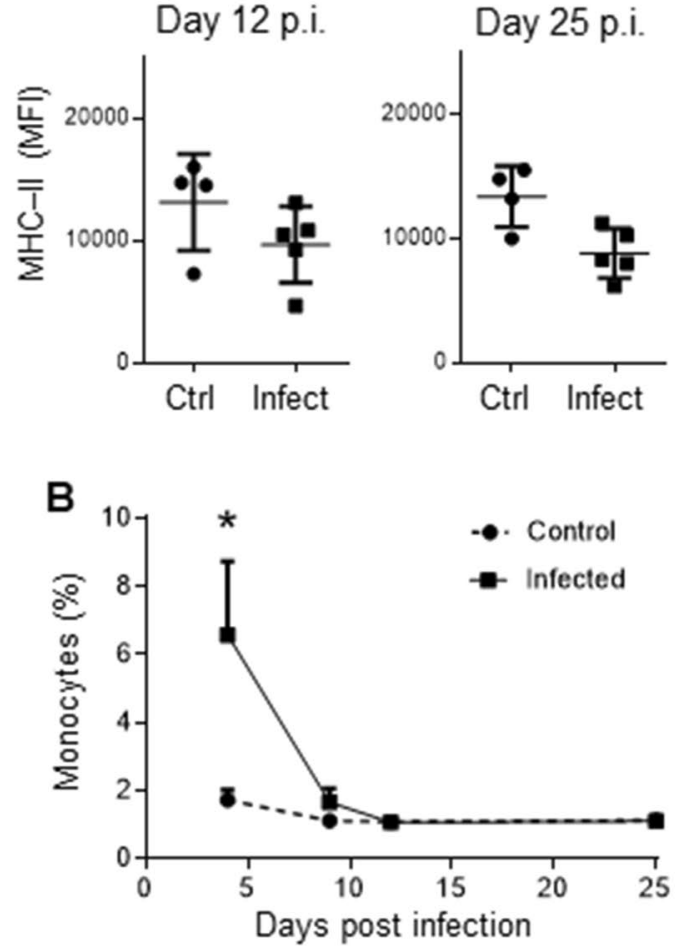

C Gated monocytes

D

Gated monocytes

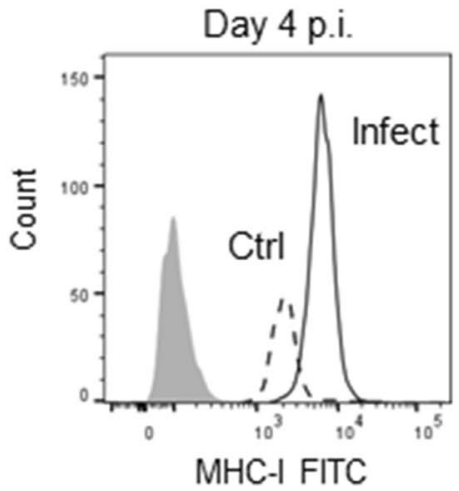

Day 4 p.i.

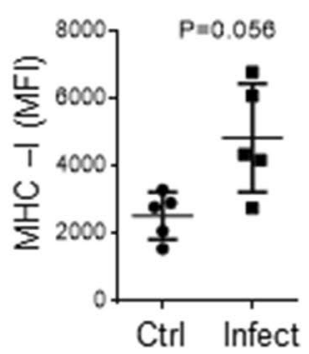

Day 9 p.i.

Day 12 p.i.
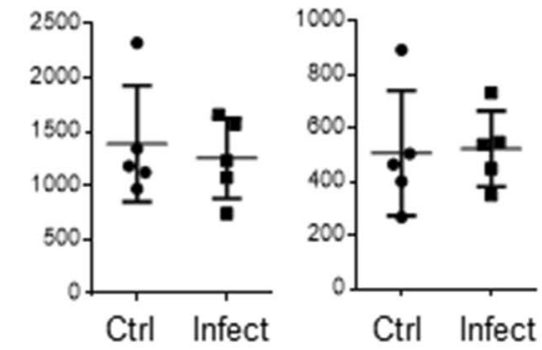


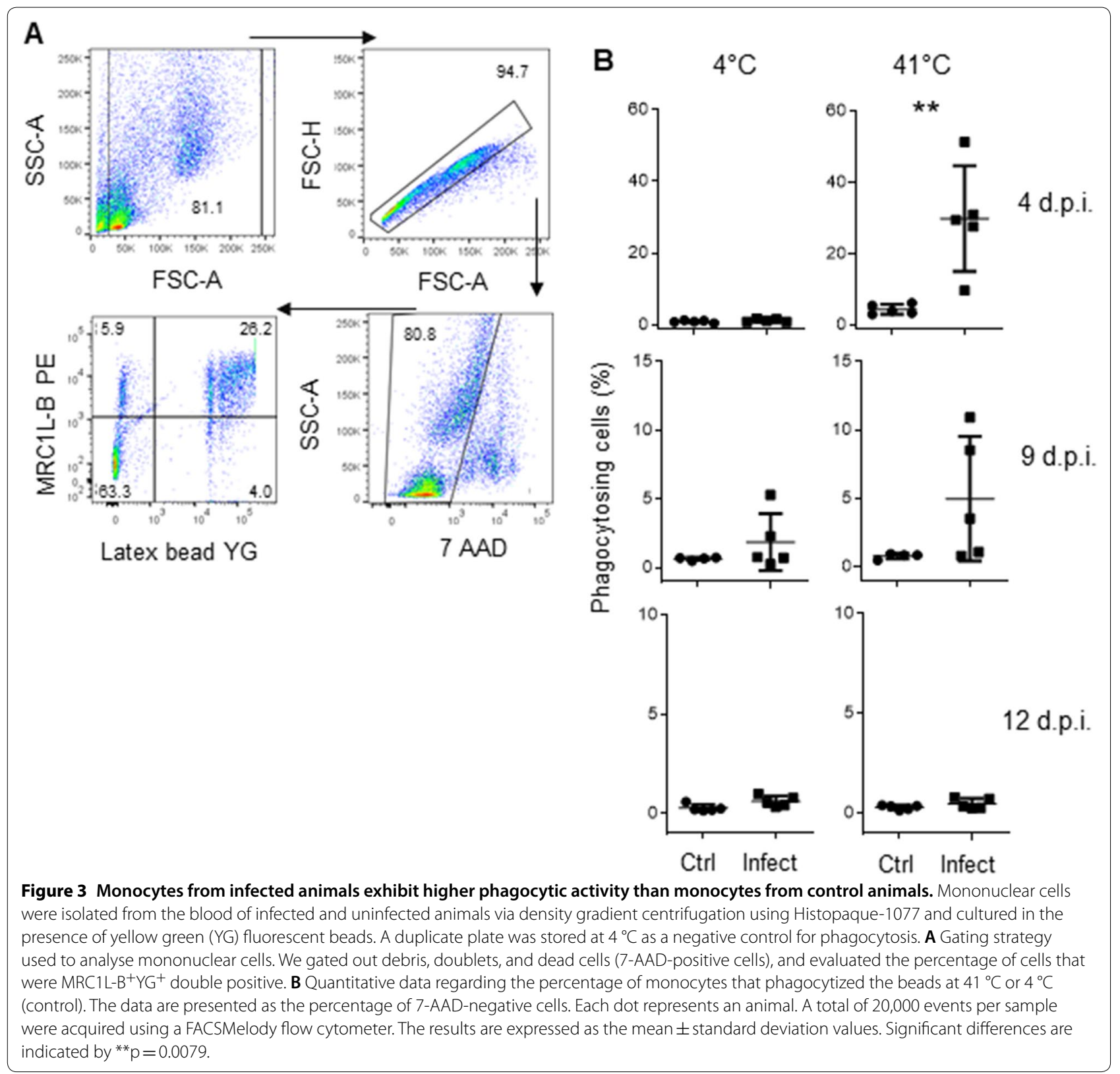

T cell proliferation and antibody production are affected in infected animals

We also investigated whether lymphocytes from infected animals have the same proliferation ability as lymphocytes from control animals. To achieve this objective, we infected 5 animals with $A v$. paragallinarum, and 5 animals (16-week-old chickens) were used as controls. Four days post infection, we confirmed the presence of $\mathrm{MHC}$ -

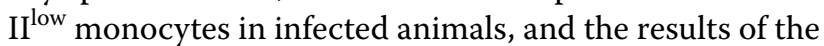
EdU proliferation assay revealed that lymphocytes from these animals were less proliferative than lymphocytes from control animals $(1.74 \pm 1.43 \%$ vs $10.21 \pm 11.12 \%$, $\mathrm{p}=0.0079$ ), as shown in Figure $4 \mathrm{~A}, \mathrm{D}$. Using antibodies, we observed that this reduction in proliferation was more pronounced for $\mathrm{CD}^{+} \mathrm{T}$ cells $(0.36 \pm 0.36 \%$ vs $1.59 \pm 0.86 \%, \mathrm{p}=0.0317)$ than for $\mathrm{CD}^{-} \mathrm{T}$ cells $(1.77 \pm 1.21 \%$ vs $8.7 \pm 10.2 \%, \mathrm{p}=0.095)$.

In this experimental group, MHC-II expression in monocytes isolated from two infected chickens (denoted with a red triangle and a red square) was lower than expected (Figure 4A, B). Intriguingly, the chicken represented by the red triangle, with an MHC-II MFI of 2722, died 6 days post infection, while the chicken represented by the red square, with an MHC-II MFI of 8882, died two 


\section{(See figure on next page.)}

Figure 4 T lymphocytes isolated from infected animals showed less proliferation than those isolated from control animals. A The MFI of MHC-II expression in monocytes and $\mathrm{MHC}-\|^{+}{ }^{M R C} 1 \mathrm{~L}^{-} \mathrm{B}^{-}$cells isolated from infected and uninfected animals. B The MFI of MHC- -1 expression in monocytes and the percentages of MHC-Illow monocytes isolated from uninfected animals, infected survivors, and infected non survivors. C Gating strategy used to analyse proliferating cells. $\mathbf{D}$ Left: the percentage of EdU-positive cells within the singlet cells. Right: the percentage of EdU-positive cells within the $\mathrm{CD}^{+}$population. Bottom: the percentage of EdU-positive cells within the $\mathrm{CD} 4^{-}$population. The results are expressed as the mean \pm standard deviation values. A total of 50,000 events per sample were acquired using a FACSMelody flow cytometer. Significant differences are indicated by ${ }^{*} p=0.0317$.

days later. Furthermore, $\mathrm{MHC}-\mathrm{II}^{+} \mathrm{MRC} 1 \mathrm{~L}-\mathrm{B}^{-}$cells isolated from the chicken represented by the red triangle also exhibited the lowest MHC-II MFI (6636). Based on MHC-II expression, we also observed the presence of two subpopulations of circulating monocytes: $\mathrm{MHC}-\mathrm{II}^{\mathrm{low}} \mathrm{M}-$ RC1L-B ${ }^{+}$and $\mathrm{MHC}-\mathrm{II}^{+} \mathrm{MRC} 1 \mathrm{~L}-\mathrm{B}^{+}$cells. The MHC-II lowMRC1L- ${ }^{+}$monocytes accounted for $93.3 \%$ and $46 \%$ of the monocytes isolated from the chickens that died 6 and 8 days post infection, respectively, while this population accounted for at most $12.8 \%$ of the monocytes in the surviving infected animals. In the uninfected animals, this population accounted for at most $1 \%$ of the monocytes. We could not correlate the death of the animals to clinical signs of the disease. Although the presence of bacterial DNA was detected in the mucosal samples by PCR, both chickens exhibited only mild facial swelling.

Considering that the main function of MHC-II molecules relates to antigen presentation, we investigated whether antibody production was compromised. Therefore, 5 days post infection, chickens were inoculated with the Newcastle disease virus (NDV) vaccine (LaSota strain). As shown in Figure 5, infected animals (16 weeks old) with circulating MHC-II ${ }^{\text {low }}$ monocytes and MRC1L$\mathrm{B}^{-}$cells with a normal MHC-II expression level (Figure 1D) on day 4 post infection produced lower titres of antibodies against NDV than uninfected chickens (16 weeks old), as evaluated on day 14 post vaccination ( $\mathrm{S} / \mathrm{P}$ ratio: $7.6 \pm 1.3$ vs $9.1 \pm 0.76, \mathrm{p}=0.0379$ ).

\section{Discussion}

The immunological response that is essential for defining the severity and physiological outcome of infectious diseases is poorly studied in infectious coryza. Available studies have evaluated only the local immune response by analysis of nasal tissue samples $[9,10]$. As a comprehensive overview of the immune system response is lacking, we evaluated the systemic effects of infection with $A v$. paragallinarum on the immune system of SPF chickens.

In the present study, we found that infected chickens developed peripheral blood monocytosis. An increase in the number of monocytes was also observed in chickens that were injected intravenously with lipopolysaccharide
(LPS), a major constituent of gram-negative bacteria [33]. Interestingly, we observed that these monocytes were characterized by decreased expression levels of the MHC-II molecule compared to those on monocytes from control animals. Furthermore, on day 4 post infection, we observed a slight increase in MHC-I expression, suggesting that these cells were exposed to a stimulus. To our knowledge, there are no previous reports indicating an association of MHC-II ${ }^{\text {low }}$ monocytes with either an effective or a defective immune response in chickens. However, a large body of work has demonstrated that in humans as well as in mice, low MHC-II expression is related to diminished $\mathrm{T}$ lymphocyte activation [34, 35]. Moreover, low monocyte HLA-DR expression is used as a robust marker of immunosuppression or immunoparalysis, as the presence of this population has been correlated with an increased risk of secondary infections leading to late morbidity and mortality in critically ill patients admitted for sepsis, trauma or postsurgical complications [36-41]. Regarding infectious coryza, it has been demonstrated that animals infected with Av. paragallinarum and then infected with $O$. rhinotracheale 3 days later, showed more severe clinical signs and higher morbidity than chickens infected with Av. paragallinarum or O. rhinotracheale alone [23]. Another study showed that simultaneous experimental infection with Av. paragallinarum and Gallibacterium anatis increased the severity of clinical signs of infectious coryza, resulting in the death of four birds [6]. In field outbreaks, it was demonstrated that Mycoplasma synoviae and Mycoplasma gallisepticum intensified clinical signs, pathological lesions, and mortality in complicated cases of infectious coryza [3-5]. These studies illustrated that secondary infections can exacerbate the clinical signs of the disease, increasing the morbidity and mortality rates. In the current study, we reported the death of two animals in the infected group. Although these chickens did not exhibit strong clinical signs of the disease, MHC-II ${ }^{\text {low }}$ monocytes accounted for more than $45 \%$ of the circulating monocytes. Conversely, this population accounted for less than $13 \%$ of the circulating monocyte population in infected survivors and less than $1 \%$ in control animals. Based on our results and the available literature, we suggest that as in humans, the presence of MHC-II ${ }^{\text {low }}$ monocytes in chickens may 


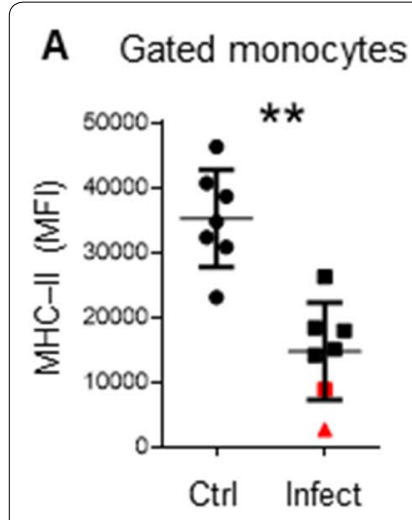

B

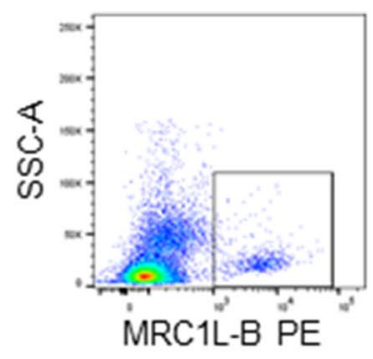

Gated

MHC-II+ MRC1L-B-
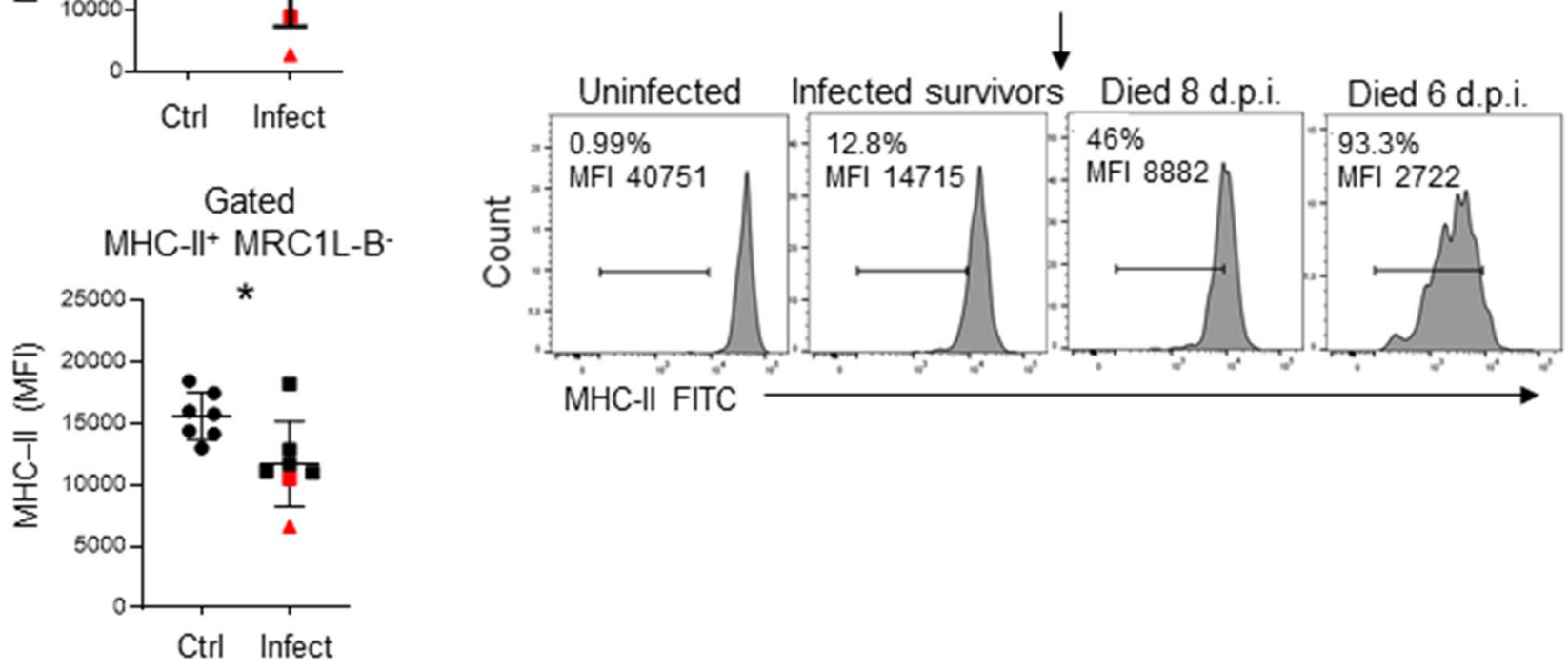

C
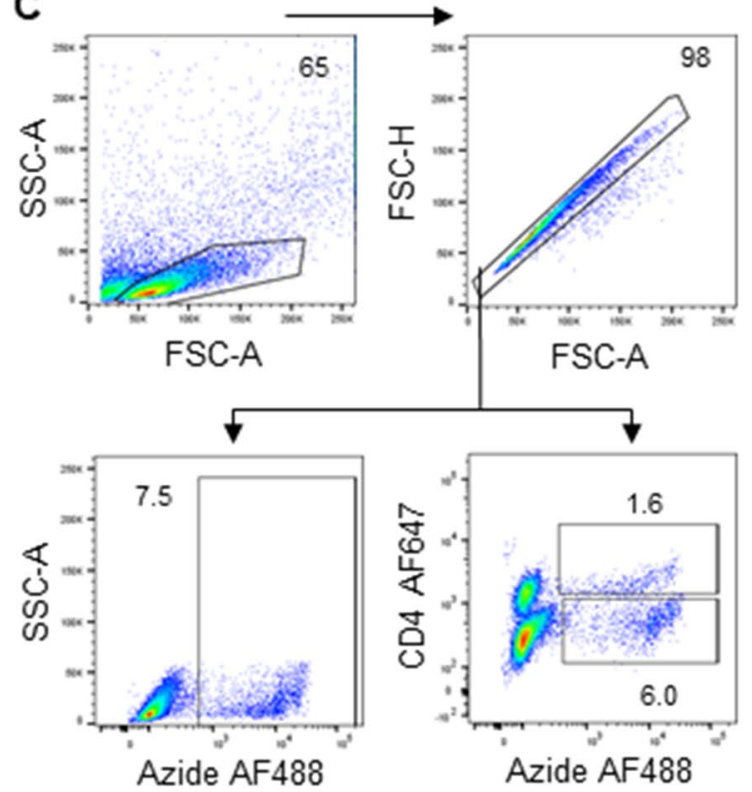
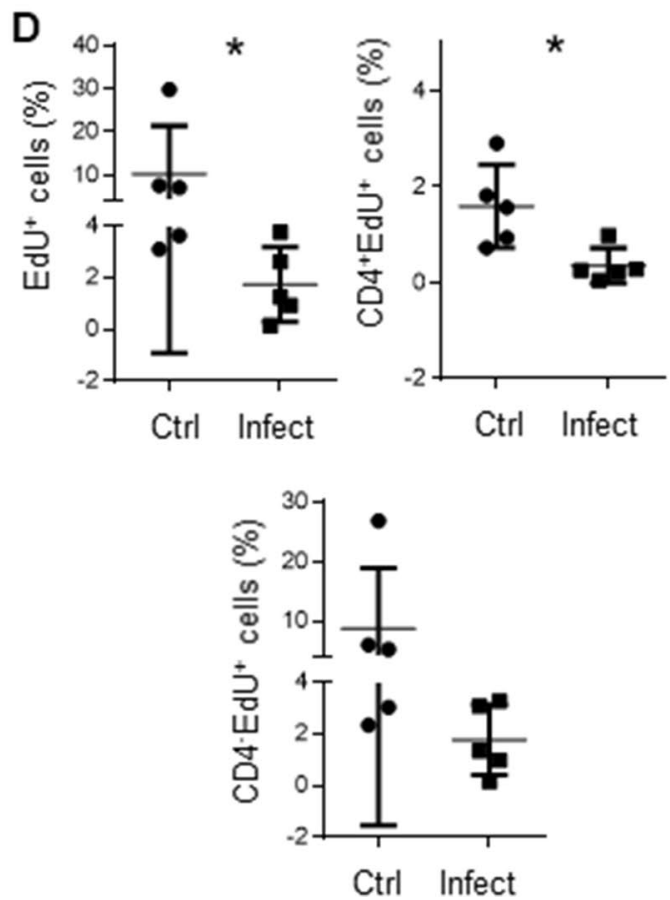


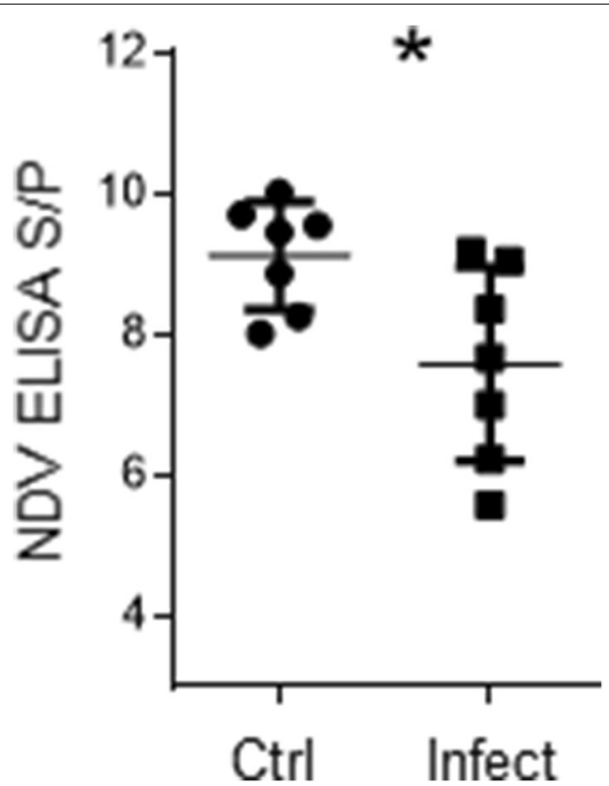

Figure 5 Lower antibody titres were produced in infected animals than in uninfected animals. Five days post infection, control and infected animals were inoculated with recombinant Newcastle disease virus (LaSota strain). On the day of vaccination, as well as 14 days post vaccination, serum samples were collected from both experimental groups. Circulating NDV-specific antibodies were assessed by enzyme-linked immunosorbent assay (ELISA). A The MFI of MHC-II molecule expression in monocytes and $\mathrm{MHC}-\|^{+}{ }^{+} \mathrm{MRC} 1 \mathrm{~L}-\mathrm{B}^{-}$ cells isolated from infected and uninfected animals is shown in Figure 1D. B ELISA results are presented as the S/P ratios. Significant differences are indicated by ${ }^{*} p=0.0379$. The results are expressed as the mean \pm standard deviation values.

be related to a dysfunctional immune response, and as a consequence, secondary infections exacerbate the clinical signs of infectious coryza, resulting in increased morbidity and mortality rates. This study also demonstrates the heterogeneity of circulating monocytes (MHC-II ${ }^{\text {low }}$ and $\mathrm{MHC}-\mathrm{II}^{+}$monocytes) during infection. A recent study demonstrated that under physiological conditions, splenic monocytes can be separated into $\mathrm{MHC}-\mathrm{II}^{\mathrm{low}}$ and MHC-II ${ }^{\text {high }}$ populations. Interestingly, MHC-II ${ }^{\text {low }}$ monocyte population is increased under inflammatory conditions induced by intraperitoneal LPS injection [42]. On the other hand, $\mathrm{Hu}$ and collaborators also demonstrated the monocytes heterogeneity and separated blood monocytes into two subpopulations based on the expression of TIM4 (a receptor that binds to phosphatidylserine) [19]. It would be of great interest to determine whether MHCII downregulation occurs in both subpopulations or if it is restricted to one population.

By studying the biological activity of the monocytes, we found that monocytes isolated from infected animals have higher phagocytic activity than control monocytes.
This observation was consistent with previous reports showing that lipopolysaccharide-tolerant human monocytes demonstrate increased phagocytic ability, although their antigen presentation capacity is impaired due to downregulation of co-stimulatory and MHC-II molecules $[35,43]$. The above mentioned results are also in line with studies in mice showing that endotoxin tolerance increases bacterial clearance [44, 45]. Regarding studies on chickens, Sun and collaborators demonstrated that in vitro phagocytosis by monocytes can also be correlated with bacterial clearance under both in vitro and in vivo conditions [46]. Thus, our results suggest that MHC-II ${ }^{\text {low }}$ monocytes may contribute to Av. paragallinarum clearance; however, future studies evaluating the antigen presentation ability of these cells are necessary.

In the field and in experimental infections, it was observed that effective clearance of Av. paragallinarum occurs, as bacteria are eliminated days after initial infection $[6,8]$. Confirming the role of immune cells in the in situ inflammatory response, infiltration of lymphocytes and heterophils (the avian counterpart of mammalian neutrophils) into the mucous membranes and lamina propria of the infraorbital sinus was demonstrated in infected animals [47]. Heterophils have the ability to clear bacteria by phagocytosing bacteria, degranulating, and generating an oxidative burst [48], and as demonstrated by Bojesen and collaborators, these cells also mediate local inflammation and tissue necrosis [49]. However, local inflammation cannot predict an inflammatory or anti-inflammatory systemic immune response. Moreover, as demonstrated by other investigators, the functional phenotype of immune cells, such as macrophages, can undergo reversible changes in response to the surrounding environment $[50,51]$. This ability was exemplified in cystic fibrosis patients, where the type 1 macrophage (M1) phenotype was the most common in nasal tissue, while circulating monocytes exhibited a tolerant M2 phenotype [35, 52]. This macrophage dichotomy (M1/2) is not established in chickens. However, a recent study provides novel evidence for the existence of these monocyte populations in chickens [42]. That study demonstrated an increase in MRC1L-B ${ }^{\text {high }} \mathrm{MHC}-\mathrm{II}^{\text {low }}$ splenic cells (possibly M2) under inflammatory conditions (induction via intraperitoneal LPS injection). Moreover, these cells characterized by high phagocytic activity produced lower amounts of inflammatory cytokines (IL$1 \beta$, IL-6, and IL-12p40) than MRC1L-B ${ }^{\text {low } M H C-I I ~ h i g h ~}$ (possibly M1) cells. Based on this information, we believe that although the occurrence of a local inflammatory immune response during Av. paragallinarum infection is indicated in previous reports, it is plausible that the circulating MHC-II ${ }^{\text {low }}$ monocytes described in the present 
study could contribute to an anti-inflammatory systemic immune response. Future research is needed to confirm or discard our hypothesis.

It was reported that a systemic anti-inflammatory immune response, termed compensatory anti-inflammatory response syndrome (CARS), acts as a counter-regulatory mechanism for maintaining homeostasis that aims to prevent overwhelming inflammation and is characterized by an impaired cellular immune response [22]. In line with this observation, we also reported that the cellular adaptive immune response could be compromised in infected chickens, as the $\mathrm{T}$ lymphocytes isolated from the blood of infected chickens were less proliferative than those isolated from control animals. This difference can be explained by $\mathrm{T}$ lymphocyte anergy or by the presence of a circulating suppressor population in cell culture. In the latter case, the activity of this suppressor may be mediated by soluble factors, as we used a TCR-independent antigen to stimulate the cells. Further studies are required to elucidate the mechanism involved in the diminished responses to mitogen stimulation in $\mathrm{T}$ lymphocytes. We also demonstrated that the ability of B cells to produce antibodies was lower in infected animals than in control animals, indicating that the humoural immune response was also compromised. In this experimental group, the surface expression level of MHC-II in MRC1L$\mathrm{B}^{-}$cells (most of which were $\mathrm{B}$ cells) from infected and control animals was similar. Strikingly, in other experimental groups, we observed reduced expression of MHC-II not only in the monocyte population but also in other $\mathrm{APC}\left(\mathrm{MHC}-\mathrm{II}^{+} \mathrm{MRC} 1 \mathrm{~L}-\mathrm{B}^{-}\right)$. We cannot attribute this variation between experimental groups to the age of the chickens, as this downregulation was observed in both 16- and 37-week-old chickens, or to the intensity of the clinical signs, as the chickens exhibited mild signs. It is possible that dysregulation of circulating B cells or other APC could be more pronounced and homogeneous in chickens that exhibit severe clinical signs of the disease or are infected with another serovar.

In this study, we generally observed mild signs of the disease. The pathogenicity of Av. paragallinarum has been correlated with the serovar, challenge method, host, and dosage [53]. We reproduced IC using an artificial intrasinus instillation method, which is different from the in-contact challenge method (similar to natural infection), and the clinical signs were less persistent and intense in our model than in the in-contact challenge model. Further studies using the in-contact challenge model or farm conditions are necessary to confirm or deny an association between clinical signs and the severity of the impaired systemic immune response. Moreover, as differences in local inflammation between serovars could exist, we cannot predict the reproducibility of the results in chickens infected with another serovar. However, this study revealed novel information regarding the systemic immune response in chickens infected with serovar B-1 that could be used as a reference point in evaluating the immune response elicited by other serovars and gram-negative bacteria.

In summary, based on the low expression of MHC-II on monocytes, reduced antibody production ability, and defective activation of $\mathrm{T}$ cells, we suggest that animals infected with Av. paragallinarum (serovar B-1) have a dysfunctional immune response that could be related to the severe clinical signs observed in complicated IC. Furthermore, as low MHC-II expression and high phagocytic activity are some of the hallmarks of tolerant monocytes (well characterized in mouse and human studies), we present the first evidence that a population of these cells is present in chickens infected with Av. paragallinarum (serovar B-1). The study of the specific molecules and mechanisms involved in the dysregulation of the innate and adaptive immune systems will contribute to the development of novel vaccines and/or therapeutic strategies to control this life-threatening disease.

\section{Supplementary information}

Supplementary information accompanies this paper at https://doi. org/10.1186/s13567-020-00840-7.

Additional file 1. Clinical sign scores of the chickens infected with $A v$. paragallinarum that were used in this study. The clinical signs observed were scored according to the following scale: 0 , no signs; 1 , nasal discharge or slight facial swelling; 2 , nasal discharge and moderate facial swelling; 3 , abundant nasal discharge and severe facial swelling; and 4 , the same signs as 3 with the addition of swollen wattles. (A) The clinical signs were recorded in the experimental group of 37-week-old chickens from which mononuclear cells were isolated and treated according to a previously determined protocol, thereby generating the results presented in Figures $1 \mathrm{~A}$ and B. (B) The clinical signs were recorded in the experimental group of 37-week-old chickens from which mononuclear cells were isolated 4, 9, 12, and 25 days post infection and treated according to a previously determined protocol, thereby generating the results presented in Figures 2 and 3. (C) The clinical signs were recorded in the experimental group of 16-week-old chickens from which mononuclear cells were isolated and treated according to a previously determined protocol, thereby generating the results presented in Figures 1C, 1D, and 5. (D) The clinical signs were recorded in the experimental group of 16-week-old chickens from which mononuclear cells were isolated and treated according to a previously determined protocol, thereby generating the results presented in Figure 4. *: Bacterial DNA detected by PCR; -: animal death.

Additional file 2. Evaluation of the presence of Av. paragallinarum in mucosal samples from infected animals and uninfected animals by PCR. Representative agarose gel electrophoresis results for PCR products amplified with primers based on the sequences of the hypervariable region in the hmtp210 gene were used to identify Av. paragallinaruminfected chickens. Line M (marker): 1000 bp DNA ladder, NTC: no-template control, $C(+)$ : positive control, and C(-): negative control.

Additional file 3. Gating strategy used to analyse whole blood samples.

\section{Abbreviations}

AF: Alexa Fluor; Av. paragallinarum: Avibacterium paragallinarum; CARS: compensatory anti-inflammatory response syndrome; DAMP: damage-associated 
molecular patterns; ConA: concanavalin A; ChS: chicken Serum; D-PBS: Dulbecco's phosphate-buffered saline; EDTA: ethylenediamine tetraacetic acid: EdU: 5-Ethynyl-2'-deoxyuridine; FACS: fluorescence-activated cell sorting; FBS: foetal bovine serum; IC: infectious coryza; MHC-I: major histocompatibility complex class I; MHC-II: major histocompatibility complex class II; MFI: mean fluorescence intensity; NDV: Newcastle disease virus; PBMC: peripheral blood mononuclear cells; PE: phycoerythrin; PEG: polyethylene glycol; PFU: plaque forming units; qPCR: quantitative polymerase chain reaction; RPMI: Roswell Park Memorial Institute; 7-AAD: 7-Aminoactinomycin D.

\section{Acknowledgements}

We thank DrVladimir Morales-Erasto for his contribution in establishing the coryza model, veterinarians Manuel Criollo and Elmer Delgado for collecting biological samples, and Freddy Ygnacio and Angela Montalvan for their technical assistance. We thank Dr Jorge Bendezú and Dr Juan Carlos Rodriguez-Lecompte for their valuable comments and suggestions regarding this study. We are also grateful to the anonymous reviewers for their constructive comments.

\section{Authors' contributions}

KLFA conceived the work with MFD, and KLFA designed the work. KLFA and APA performed the experiments. KLFA acquired, analysed, and interpreted the data of the study. KLFA wrote the paper. All authors have agreed both to be personally accountable for the author's own contributions and to ensure that questions related to the accuracy or integrity of any part of the work, even those in which the author was not personally involved, are appropriately investigated and resolved and that the resolution is documented in the literature. All authors read and approved the final manuscript.

\section{Funding}

This work was financially supported by FARVET.

\section{Availability of data and materials}

The dataset supporting the conclusions of this article is available in the Mendeley data repository. All raw data are also stored on the laboratory server and in cloud storage and will be made available upon request. We have not provided the composition of the FARMEM medium (proprietary); however, this medium will be available at a reasonable cost and in limited quantities to members of the scientific community for non-commercial purposes.

\section{Ethics approval and consent to participate}

All experiments were performed according to the Guide for the Care and Use of Laboratory Animals. The protocol (code: CEBA 2020-8) was approved by the Institutional Animal Care and Use Committee of the Faculty of Veterinary Medicine, National University of San Marcos, Lima, Peru. This study was carried out in compliance with the guidelines provided by the National Agrarian Health Service (SENASA, Revised 2007).

\section{Consent for publication}

Not applicable.

\section{Competing interests}

KLFA and APA are employees of FARVET. MFD is the CEO of FARVET. The authors declare no competing financial and/or non-financial interests in relation to this study.

Received: 1 April 2020 Accepted: 2 September 2020

Published online: 25 September 2020

\section{References}

1. Calderón EN, Thomas K, Morales-Erasto V et al (2010) Identification of Avibacterium paragallinarum serovar B-1 from severe infectious coryza outbreaks in Panama. Avian Dis Dig 5:e38-e39

2. Blackall PJ (1999) Infectious coryza: overview of the disease and new diagnostic options. Clin Microbiol Rev 12:627-632

3. Sarika N, Devigasri C, Sankar S, Mini M (2019) A report of natural concurrent infection with Avibacterium paragallinarum and Mycoplasma gallisepticum in chicken. TPI 8:16-18
4. Sandoval AVE, Terzolo HR, Blackall PJ et al (1994) Case report-complicated infectious coryza outbreaks in Argentina. Avian Dis 38:672-678

5. Rimler R, Davis R, Page R, Kleven S (1978) Infectious coryza : Preventing complicated coryza with Haemophilus gallinarum and Mycoplasma gallisepticum bacterins. Avian Dis 22:140-150

6. Paudel S, Hess M, Hess C (2017) Coinfection of Avibacterium paragallinarum and Gallibacterium anatis in specific-pathogen-free chickens complicates clinical signs of infectious coryza, which can be prevented by vaccination. Avian Dis 61:55-63

7. Kume K, Sawata A, Nakai T, Matsumoto M (1983) Serological classification of Haemophilus paragallinarum with a hemagglutinin system. J Clin Microbiol 17:958-964

8. Balouria A, Deshmukh S, Banga HS et al (2019) Early migration pattern of Avibacterium paragallinarum in the nasal passage of experimentally infected chicken and Japanese quail by immunohistochemistry. Avian Pathol 48:168-177

9. Boucher CE, Theron CW, Hitzeroth AC, Bragg RR (2015) Regulation of chicken immunity-related genes and host response profiles against Avibacterium paragallinarum pathogen challenge. Vet Immunol Immunopathol 167:70-74

10. Boucher CE, Theron CW, Jansen AC, Bragg RR (2014) Transcriptional profiling of chicken immunity-related genes during infection with Avibacterium paragallinarum. Vet Immunol Immunopathol 158:135-142

11. Bianchi ME (2007) DAMPs, PAMPs and alarmins: all we need to know about danger. J Leukoc Biol 81:1-5

12. Matzinger $P$ (1994) Tolerance, danger, and the extended family. Annu Rev Immunol 12:991-1045

13. Sharma JM (1991) Overview of the avian immune system. Vet Immunol Immunopathol 30:13-17

14. Klasing KC (1998) Avian macrophages: regulators of local and systemic immune responses. Poult Sci 77:983-989

15. Giansanti F, Giardi M, Botti D (2007) Avian cytokines—an overview. Curr Pharm Des 12:3083-3099

16. Lopez-Castejon G, Brough D (2011) Understanding the mechanism of IL-1 $\beta$ secretion. Cytokine Growth Factor Rev 22:189-195

17. He H, Lowry VK, Swaggerty CL et al (2005) In vitro activation of chicken leukocytes and in vivo protection against Salmonella enteritidis organ invasion and peritoneal S. enteritidis infection-induced mortality in neonatal chickens by immunostimulatory CpG oligodeoxynucleotide. FEMS Immunol Med Microbiol 43:81-89

18. Kim WH, Lillehoj HS, Min W (2017) Evaluation of the immunomodulatory activity of the chicken NK-lysin-derived peptide cNK-2. Sci Rep 7:45099

19. Hu T, Wu Z, Bush SJ et al (2019) Characterization of subpopulations of chicken mononuclear phagocytes that express TIM4 and CSF1R. J Immunol 202:1186-1199

20. Adib-Conquy M, Cavaillon JM (2009) Compensatory anti-inflammatory response syndrome. Thromb Haemost 101:36-47

21. Antoniades CG, Berry PA, Wendon JA, Vergani D (2008) The importance of immune dysfunction in determining outcome in acute liver failure. J Hepatol 49:845-861

22. Ward NS, Casserly B, Ayala A (2008) The compensatory anti-inflammatory response syndrome (CARS) in critically ill patients. Clin Chest Med 29:617-625

23. Morales-Erasto V, Falconi-Agapito F, Luna-Galaz GA et al (2016) Coinfection of Avibacterium paragallinarum and Ornithobacterium rhinotracheale in chickens from Peru. Avian Dis 60:75-78

24. Soriano VE, Longinos GM, Fernández RP et al (2004) Virulence of the nine serovar reference strains of Haemophilus paragallinarum. Avian Dis 48:886-889

25. Morales Ruiz S, Bendezu J, Choque Guevara R et al (2018) Development of a lateral flow test for the rapid detection of Avibacterium paragallinarum in chickens suspected of having infectious coryza. BMC Vet Res 14:411

26. Alvarez KLF, Poma-acevedo A, Fernández-Sánchez M, Fernández-Díaz M (2020) An EdU-based flow cytometry assay to evaluate chicken T lymphocyte proliferation. BMC Vet Res 16:230

27. Balic A, Garcia-Morales C, Vervelde L et al (2014) Visualisation of chicken macrophages using transgenic reporter genes: Insights into the development of the avian macrophage lineage. Development 141:3255-3265 
28. Mast J, Goddeeris BM, Peeters K et al (1998) Characterisation of chicken monocytes, macrophages and interdigitating cells by the monoclonal antibody KUL01. Vet Immunol Immunopathol 61:343-357

29. Parker A, Kaufman J (2017) What chickens might tell us about the MHC class II system. Curr Opin Immunol 46:23-29

30. Mitchell EK, Mastroeni P, Kelly AP, Trowsdale J (2004) Inhibition of cell surface MHC class II expression by Salmonella. Eur J Immunol 34:2559-2567

31. Milillo MA, Trotta A, Serafino A et al (2019) Bacterial RNA Contributes to the down-modulation of MHC-II expression on monocytes/macrophages diminishing CD4+ T cell responses. Front Immunol 10:2181

32. Naghizadeh M, Larsen FT, Wattrang E et al (2019) Rapid whole blood assay using flow cytometry for measuring phagocytic activity of chicken leukocytes. Vet Immunol Immunopathol 207:53-61

33. Bowen OT, Dienglewicz RL, Wideman RF, Erf GF (2009) Altered monocyte and macrophage numbers in blood and organs of chickens injected i.v. with lipopolysaccharide. Vet Immunol Immunopathol 131:200-210

34. Wolk K, Döcke WD, Von Baehr V et al (2000) Impaired antigen presentation by human monocytes during endotoxin tolerance. Blood 96:218-223

35. del Fresno C, García-Rio F, Gómez-Piña V et al (2009) Potent phagocytic activity with impaired antigen presentation identifying lipopolysaccharide-tolerant human monocytes: demonstration in isolated monocytes from cystic fibrosis patients. J Immunol 182:6494-6507

36. Monneret G, Lepape A, Voirin N et al (2006) Persisting low monocyte human leukocyte antigen-DR expression predicts mortality in septic shock. Intensive Care Med 32:1175-1183

37. Lekkou A, Karakantza M, Mouzaki A et al (2004) Cytokine production and monocyte HLA-DR expression as predictors of outcome for patients with community-acquired severe infections. Clin Diagn Lab Immunol 11:161-167

38. Monneret $G$, Finck ME, Venet F et al (2004) The anti-inflammatory response dominates after septic shock: association of low monocyte HLA-DR expression and high interleukin-10 concentration. Immunol Lett 95:193-198

39. Venet F, Tissot S, Debard AL et al (2007) Decreased monocyte human leukocyte antigen-DR expression after severe burn injury: correlation with severity and secondary septic shock. Crit Care Med 35:1910-1917

40. Vester H, Dargatz P, Huber-Wagner S et al (2015) HLA-DR expression on monocytes is decreased in polytraumatized patients. Eur J Med Res 20:1-9
41. Kim OY, Monsel A, Bertrand M et al (2010) Differential down-regulation of HLA-DR on monocyte subpopulations during systemic inflammation. Crit Care 14:R61

42. Yu K, Gu MJ, Pyung YJ et al (2020) Characterization of splenic MRC1hiMHCIllo and MRC1loMHCIlhi cells from the monocyte/macrophage lineage of White Leghorn chickens. Vet Res 51:1-16

43. Muthukuru M, Cutler CW (2008) Antigen capture of Porphyromonas gingivalis by human macrophages is enhanced but killing and antigen presentation are reduced by endotoxin tolerance. Infect Immun 76:477-4857

44. Murphey ED, Fang G, Varma TK, Sherwood ER (2007) Improved bacterial clearance and decreased mortality can be induced by LPS tolerance and is not dependent upon IFN- $\gamma$. Shock 27:289-295

45. Varma TK, Durham M, Murphey ED et al (2005) Endotoxin priming improves clearance of pseudomonas aeruginosa in wild-type and interleukin-10 knockout mice. Infect Immun 73:7340-7347

46. Sun SF, Pan QZ, Hui X et al (2008) Stronger in vitro phagocytosis by monocytes-macrophages is indicative of greater pathogen clearance and antibody levels in vivo. Poult Sci 87:1725-1733

47. Trujillo-Ruíz HH, Shivaprasad HL, Morales-Erasto V et al (2016) Virulence of serovar C-1 strains of Avibacterium paragallinarum. Avian Dis 60:837-840

48. Kogut MH, Genovese KJ, Lowry VK (2001) Differential activation of signal transduction pathways mediating phagocytosis, oxidative burst, and degranulation by chicken heterophils in response to stimulation with opsonized Salmonella enteritidis. Inflammation 25:7-15

49. Bojesen AM, Petersen KD, Nielsen OL et al (2004) Pasteurella multocida infection in heterophil-depleted chickens. Avian Dis 48:463-470

50. Sica A, Mantovani A (2012) Plasticity and polarization. J Clin Invest 122:787-795

51. Italiani P, Boraschi D (2014) From monocytes to M1/M2 macrophages: phenotypical vs functional differentiation. Front Immunol 5:514

52. Claeys S, Van Hoecke H, Holtappels G et al (2005) Nasal polyps in patients with and without cystic fibrosis: a differentiation by innate markers and inflammatory mediators. Clin Exp Allergy 35:467-472

53. Zhao Q, Sun Y, ni, Zhang X xiao, et al (2010) Evaluation of two experimental infection models for Avibacterium paragallinarum. Vet Microbiol 141:68-72

\section{Publisher's Note}

Springer Nature remains neutral with regard to jurisdictional claims in published maps and institutional affiliations.
Ready to submit your research? Choose BMC and benefit from:

- fast, convenient online submission

- thorough peer review by experienced researchers in your field

- rapid publication on acceptance

- support for research data, including large and complex data types

- gold Open Access which fosters wider collaboration and increased citations

- maximum visibility for your research: over $100 \mathrm{M}$ website views per year

At $\mathrm{BMC}$, research is always in progress.

Learn more biomedcentral.com/submissions 